\title{
Higher genome variability within metabolism genes associates with recurrent Clostridium difficile infection
}

\author{
Maria Kulecka ${ }^{1,2}$, Edyta Waker ${ }^{3}$, Filip Ambrozkiewicz ${ }^{1}$, Agnieszka Paziewska ${ }^{1,2}$, Karolina Skubisz², Patrycja Cybula², \\ Łukasz Targoński ${ }^{4}$, Michał Mikula ${ }^{1}$, Jan Walewski ${ }^{4}$ and Jerzy Ostrowski ${ }^{1,2^{*}}$
}

\begin{abstract}
Background: Clostridium difficile (C. difficile) is a major source of healthcare-associated infection with a high risk of recurrence, attributable to many factors such as usage of antibiotics, older age and immunocompromised status of the patients. C. difficile has also a highly diverse genome, which may contribute to its high virulence. Herein we examined whether the genome conservation, measured as non-synonymous to synonymous mutations ratio (dN/ dS) in core genes, presence of single genes, plasmids and prophages increased the risk of reinfection in a subset of 134 C. difficile isolates from our previous study in a singly hemato-oncology ward.
\end{abstract}

Methods: C. difficile isolates were subjected to whole-genome sequencing (WGS) on lon Torrent PGM sequencer. Genomes were assembled with MIRA5 and annotated with prokka and VRprofile. Logistic regression was used to asses the relationship between single gene presence and the odds of infection recurrence. DN/dS ratios were computed with codeml. Functional annotation was conducted with eggNOG-Mapper.

Results: We have found that the presence of certain genes, associated with carbon metabolism and oxidative phosphorylation, increased the odds of infection recurrence. More core genes were under positive selective pressure in recurrent disease isolates - they were mostly associated with the metabolism of aminoacids. Finally, prophage elements were more prevalent in single infection isolates and plasmids did not influence the odds of recurrence.

Conclusions: Our findings suggest higher genetic plasticity in isolates causing recurrent infection, associated mainly with metabolism. On the other hand, the presence of prophages seems to reduce the isolates' virulence.

Keywords: Clostridium difficile, Infection, Recurrence, Whole genome sequencing, Prophage

\section{Background}

Clostridium difficile (reclassified in 2016 into a new Clostridiodes genus, along with Clostridium mangenotii, with which it shares a $94.7 \%$ similarity within $16 \mathrm{~s}$ rRNA gene [1]) is an anaerobic, spore-forming, Gram-positive

\footnotetext{
* Correspondence: jostrow@warman.com.pl

'Department of Genetics, Maria Sklodowska-Curie National Research Institute of Oncology, Roentgena 5, 02-781 Warsaw, Poland

${ }^{2}$ Department of Gastroenterology, Hepatology and Clinical Oncology, Centre of Postgraduate Medical Education, 02-781, Warsaw, Poland

Full list of author information is available at the end of the article
}

bacterium, prevalent in the environment, as well as human gastrointestinal tract: it is mainly present in infants $[2,3]$, in whom the asymptomatic colonization occurs. On the other hand, in adults, $C$. difficile colonization is characterized by life-threatening infection, with symptoms ranging from moderate diarrhea to severe colitis and/or megacolon $[4,5]$. In Europe, the majority (74.6\%) of $C$. difficile cases are healthcare-associated (HA). The mean incidence per 10,000 patient-days is at 2.38, but some countries, such as Estonia, Lithuania and Poland

C C The Author(s). 2021 Open Access This article is licensed under a Creative Commons Attribution 4.0 International License, which permits use, sharing, adaptation, distribution and reproduction in any medium or format, as long as you give appropriate credit to the original author(s) and the source, provide a link to the Creative Commons licence, and indicate if changes were made. The images or other third party material in this article are included in the article's Creative Commons licence, unless indicated otherwise in a credit line to the material. If material is not included in the article's Creative Commons licence and your intended use is not permitted by statutory regulation or exceeds the permitted use, you will need to obtain permission directly from the copyright holder. To view a copy of this licence, visit http://creativecommons.org/licenses/by/4.0/ The Creative Commons Public Domain Dedication waiver (http://creativecommons.org/publicdomain/zero/1.0/) applies to the data made available in this article, unless otherwise stated in a credit line to the data. 
present with much higher numbers [6]. In large European hospital surveys from 10\% [7] to 16\% [6] Clostridium difficile infection (CDI) cases are associated with major complications, requiring admission to the intensive care unit and resulting in the death rate of 7 and $4 \%$ respectively.

Another major concern when dealing with CDI is its tendency of recurrence which, according to the European Society of Clinical Microbiology and Infectious Diseases, is defined as a relapse of CDI clinical symptoms within 2-8 weeks of successful treatment of the initial episode. The recurrent CDI may be due to a relapse of the previous CDI by the same strain or reinfection by a different strain [8-10]. While distinguishing of recurrence due to relapse or from recurrence due to reinfection is not feasible in daily practice, the method of choice in this distinction is bacterial genotyping [9]. Reported recurrence rates vary between 5 and $50 \%$, but most of them are between 10 and 20\% [11]. Various recurrence risk factors have been identified, including continued use of antibiotics not associated with CDI treatment [12], particularly cephalosporins [13, 14], older age $[12,15]$, HA diseases $[15,16]$, length of hospitalization [15] and usage of gastric acid suppressors such as proton pump inhibitors [10, 12, 17, 18]. Immunocompromised patients also typically present a higher risk of infection recurrence $[19,20]$.

In addition, the high plasticity of $C$. difficile genome may also account for its virulence and notorious recurrence. Sequenced $C$. difficile genomes' size typically ranges from 4.1 to $4.3 \mathrm{Mb}$ [21-24] and is much larger not only than most of the related species but also most of the Firmicutes phylum. A large genome can be a sign of exceptional adaptability to various conditions, often for prolonged periods [25]. Indeed, a large number of differentially expressed genes during infection were found to be associated with adaptation mechanisms such as stress response and sporulation [26]. The C. difficile 630 genome was also found to contain an unusually high proportion (11\%) of mobile elements, including transposons and prophages [27]. The horizontal gene transfer, occurring through these elements is particularly important in the acquisition of resistance to various antimicrobial agents [24]. Finally, the $C$. difficile genome can be altered through point mutations and inversions: in the comparison between 3 strains: 630, R20291 and CD196 39 variations such as these were found [23, 28].

In this context, the aim of our work was twofold. Firstly, to investigate and establish the core genome and pangenome of Clostridial species recovered from patients with single and multiple CDIs hospitalized in a single hemato-oncology ward through a period of ten years, both on genetic and functional level. Secondly, to investigate the $\mathrm{dN} / \mathrm{dS}$ ratio in the core genome. This data was used to compare strains, which cause recurring infections to those, which affected the patient only once.

\section{Results \\ Clostridium difficile core genome}

There were 965 core genes discovered (i.e. present in more than $90 \%$ of samples) shared between isolates from ST1 and ST42. Apart from 208 proteins with poorly characterized function, the most abundant COG categories concerned metabolism (including carbohydrate and amino acid metabolism), information storage and processing (transcription and translation) and cellular processes and signaling (signal transduction and cell wall biogenesis) (Fig. 1, Supplementary Table 1). 135 KEGG Pathways (on a third level of classification) were represented in the common core genome (Supplementary Table 2). The most represented pathways (i.e. the ones with the highest ratio of present genes to the total number of KEGG orthologies) are associated with membrane transport, aminoacid, carbohydrate and lipid metabolism, bacterial cell motility, genetic information processing, energy metabolism and metabolism of cofactors and vitamins (Fig. 2). 62\% pathways present within the core genome are associated with metabolism.

\section{Specific gene presence as a predictor of recurrence}

In the logistic regression model, there were 5264 genes tested; while 192 reached statistical significance at a nominal $p$-value of 0.05 , none of them were significant after correction for multiple hypothesis testing with the FDR method (Supplementary Table 3). 7 pathways are enriched in gene set which gives higher odds of infection recurrence, however, in only one of them the enrichment score reaches the highest value at rank smaller than 192: Oxidative phosphorylation (Table 1, Supplementary Table 4).

\section{Gene conservation differences between recurrent and single infection}

515 core genes were included in this analysis. Sequences were analyzed separately for recurrent and one-time infections. For recurrent infections, 65 genes had sites under positive selection, while for single infections this number was at 17.25 genes under positive selection only in recurrent sequences could be functionally annotated with KEGG pathways. Most of them are associated with metabolism, mainly of aminoacids and secondary metabolites. Other genes of interest include toxin $\mathrm{B}$ and cheC, involved in bacterial chemotaxis (Table 2, Supplementary Table 5).

\section{Mobile genetic elements}

Three different plasmids were discovered in our strains: pCD6, pCDBI1 and DSM 1296. Plasmids were present 


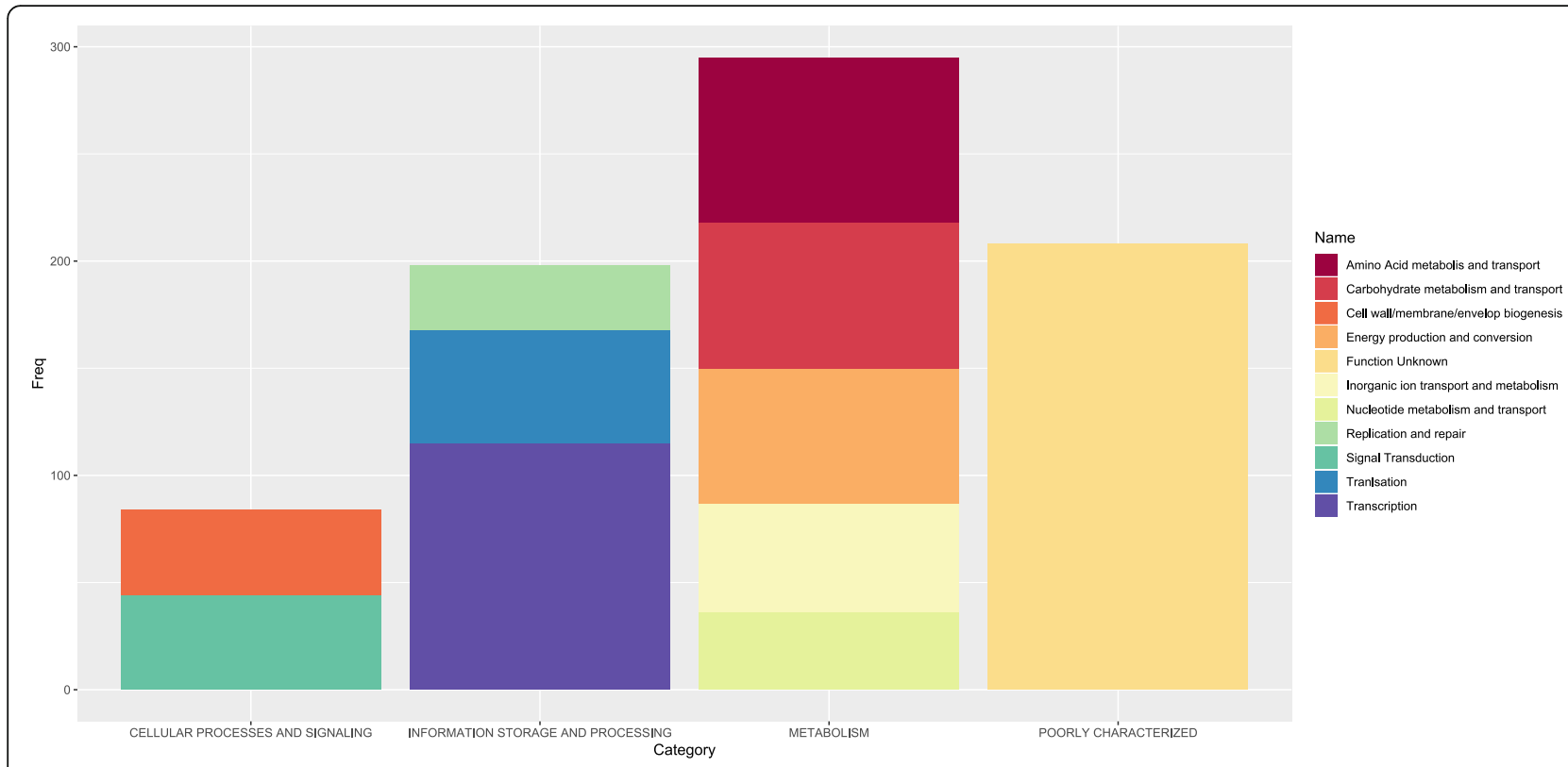

Fig. 1 Main core gene categories as characterized by COG classification

in 5\% (5 out of 98) strains which cause recurrent infection and in $11 \%$ strains which did not (4 out of 36). This difference is not statistically significant ( $p$-value 0.25 , Fisher's exact test, Table 3).

Eleven prophage elements differed in frequency between single and recurrent infections at a nominal $p$ value $<0.05$, however, none of them remained significant after multiple hypothesis testing correction. Most of them originated from phages CD119 and C2 (Table 4, Supplementary Table 6).

\section{Discussion}

The $C$. difficile genome is subject to constant changes, as estimated, it acquires between 1 and 2 mutations per genome per year $[25,29]$. However, not all mutations are viable, and some clones may become subject to

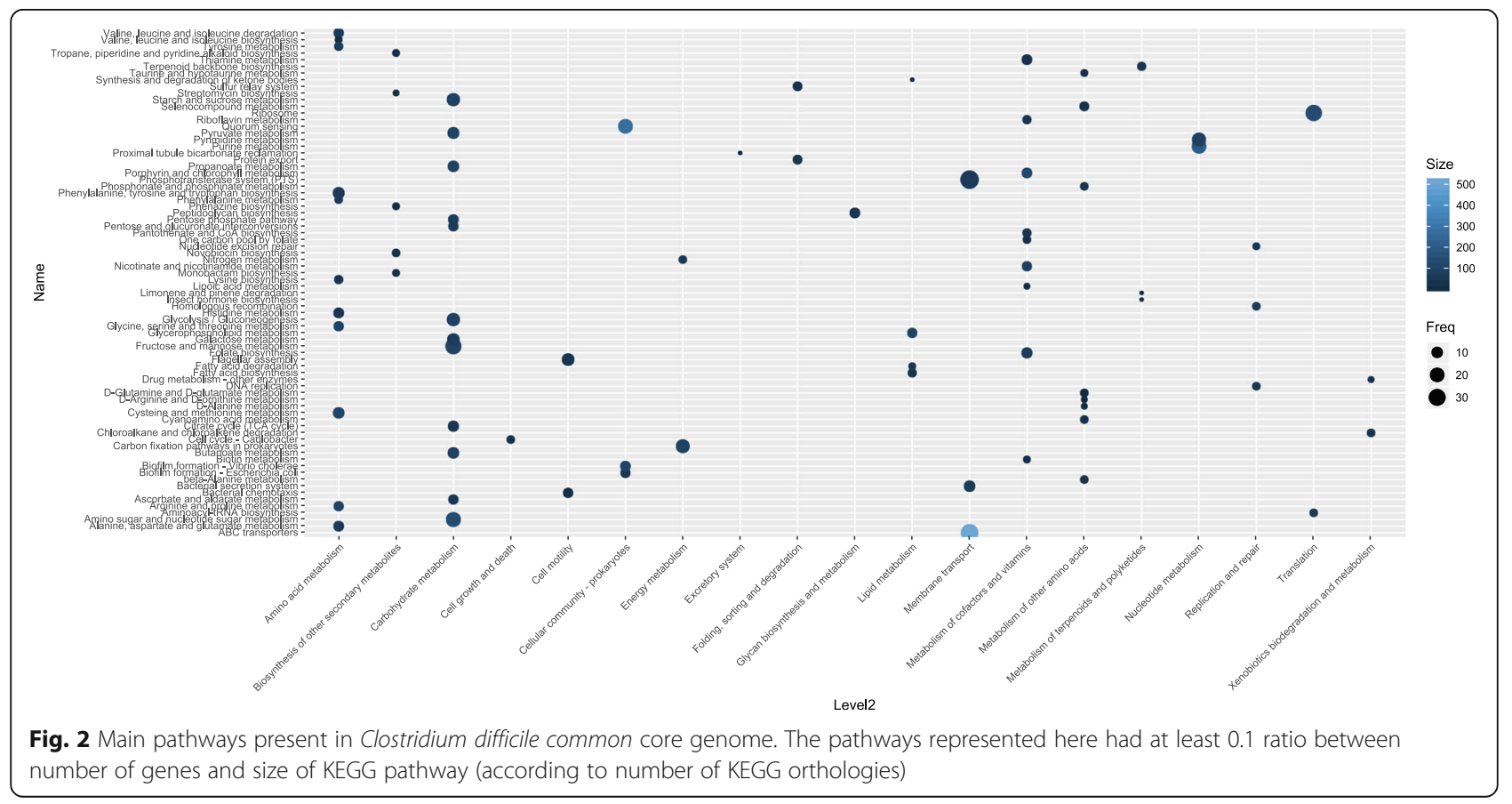


Table 1 Gene set enrichment analysis for genes ranked according to odds of infection recurrence. Size - total size of pathway in tested dataset, ES - enrichment score, NES - normalized enrichment score, pvalue - $p$-value in GSEA analysis (permutation test), padjust - pvalue after adjustment for multiple testing, rank - rank with peak enrichment score, core enrichment - gene names (if available) present in core enrichment. Adjusted $p$-values $<0.05$ were considered significant

\begin{tabular}{|c|c|c|c|c|c|c|c|c|}
\hline ID & Description & setSize & ES & NES & pvalue & padjust & rank & core enrichment \\
\hline ko00190 & $\begin{array}{l}\text { Oxidative } \\
\text { phosphorylation }\end{array}$ & 15 & 0.87 & 2.12 & $\begin{array}{l}2.19 \mathrm{E}- \\
04\end{array}$ & $\begin{array}{l}1.22 \mathrm{E}- \\
02\end{array}$ & 160 & ntpG/ntpl/atpD/ntpB/ppaC/hydA \\
\hline ko01200 & Carbon metabolism & 67 & 0.50 & 1.71 & $\begin{array}{l}9.59 \mathrm{E}- \\
04\end{array}$ & $\begin{array}{l}2.07 \mathrm{E}- \\
02\end{array}$ & 899 & $\begin{array}{l}\text { ato 1/acoB/cooS1/rpiB/fdhF/serA/ppaC/acoC/fwdE/pgk/glcK/fba2/pyc/ } \\
\text { bcd_1/tal/tklB/pfkB/pgi/dpaL/fbp/nadB/rpe/dpaL/nifJ/gap }\end{array}$ \\
\hline ko01120 & $\begin{array}{l}\text { Microbial } \\
\text { metabolism in } \\
\text { diverse environments }\end{array}$ & 199 & 0.37 & 1.47 & $\begin{array}{l}1.11 \mathrm{E}- \\
03\end{array}$ & $\begin{array}{l}2.07 \mathrm{E}- \\
02\end{array}$ & 1245 & $\begin{array}{l}\text { group_10292/ato1/mngAacoB/licR/cooS1/rpiB/fdhF/serA/group_3100/ } \\
\text { group_15830/ppaC/argD/group_10260/acoC/fwdE/group_18370/group_- } \\
\text { 14018/mt/A/pyrK/group_14004/group_20309/pgk/hemB/glcK/fba2/pyc/ } \\
\text { cobA/leuC/group_7776/bcd_1/group_1934/dfa1/group_12907/group_ } \\
\text { 4079/tal/group_11132/tk/B//ysC/rnhA/pfkB/group_11374/pgi/group_ } \\
\text { 7372/group_11044/fbp//nadB/group_607/asrA/asrB/MA20_09190/rpe/ } \\
\text { group_12912/thrC/group_1435/group_1680/nifJ/gap/hom/rnhAadhE/ } \\
\text { xdhA1/fucA/acsD/group_16780/group_14000/asrC/group_7768/icd/ytjP/ } \\
\text { sucD/group_16251/group_8676/rpiB/gutB/algC/gatB/hom/rpe/cooS1/ } \\
\text { group_18922/pmmB/group_18142 }\end{array}$ \\
\hline ko03010 & Ribosome & 25 & 0.66 & 1.82 & $\begin{array}{l}1.58 \mathrm{E}- \\
03\end{array}$ & $\begin{array}{l}2.20 \mathrm{E}- \\
02\end{array}$ & 636 & rpsK/rpsS/rpsE/rpsL/rp/O/rp/B/rplA/rpmH/rpmD \\
\hline ko01130 & $\begin{array}{l}\text { Biosynthesis of } \\
\text { antibiotics }\end{array}$ & 118 & 0.41 & 1.53 & $\begin{array}{l}3.07 \mathrm{E}- \\
03\end{array}$ & $\begin{array}{l}3.10 \mathrm{E}- \\
02\end{array}$ & 922 & $\begin{array}{l}\text { dxs/ato-1/acoB/ispD/rpiB/serA/argD/group_10260/lysN/acoC/purH/aspC/ } \\
\text { pgk/ilvC/glcK/fba2/argJ/group_7776/galU/tal/tk/B/lysC/pabC/pfkB/ } \\
\text { group_11374/ilvB/pgi/group_7372/dpaL/glmS/argB/fbp/nadB/argC/rpe/ } \\
\text { dpaL/nifJ/gap/hom/group_15453 }\end{array}$ \\
\hline ko01210 & $\begin{array}{l}\text { 2-Oxocarboxylic acid } \\
\text { metabolism }\end{array}$ & 19 & 0.68 & 1.77 & $\begin{array}{l}3.33 \mathrm{E}- \\
03\end{array}$ & $\begin{array}{l}3.10 \mathrm{E}- \\
02\end{array}$ & 799 & $\operatorname{argD/lysN/aspC/ilvC/argJ/leuC/lysC/pabC/ilvB/argB/argC}$ \\
\hline ko00710 & $\begin{array}{l}\text { Carbon fixation in } \\
\text { photosynthetic } \\
\text { organisms }\end{array}$ & 11 & 0.78 & 1.75 & $\begin{array}{l}4.75 \mathrm{E}- \\
03\end{array}$ & $\begin{array}{l}3.79 \mathrm{E}- \\
02\end{array}$ & 1223 & rpiB/pgk/fba2/tklB/fbp/rpe/gap/rpiB/rpe \\
\hline
\end{tabular}

purifying selection. The selective pressure can be described with the $\mathrm{dN} / \mathrm{dS}$ ratio, i.e. the ratio of nonsynonymous to synonymous mutations. The $\mathrm{dN} / \mathrm{dS}$ ratio significantly smaller than 1 suggests strong purifying selection, while in most $C$. difficile genomes the reverse situation is observed where the $\mathrm{dN} / \mathrm{dS}$ is actually higher than $1[24,30]$. This suggests less efficient purging of novel mutations, possibly contributing to C. difficile high genetic diversity and adaptability. With such plasticity and diversity, it is difficult to establish the exact size of $C$. difficile core genome and pangenome. Usually, the orders of magnitude of about 1000 genes are given [31, 32], but some researchers give figures as high as 3000 [33], which would be the most of $C$. difficile genome. Nevertheless, the estimated size of the core genome usually varies between $16 \%$ [34] and 24\% [31], which is much lower than most bacterial species. For instance, in pathogenic Streptococcus agalactiae, the core genome constitutes about $80 \%$ of the whole genome, in Helicobacter pylori 77 and $46 \%$ in Streptococcus pneumoniae [35]. On the other hand, the size of the core and essential genome was estimated to be composed of 404 genes [36], a number comparable to other bacterial species, such as Pseudomonas aeruginosa (321 genes [37]) and Yersinia pestis (about 500 genes [38]).
The $C$. difficile core genome is usually estimated to comprise about 1000 genes [31], involved mainly in pathways related to metabolism (of aminoacids and carbohydrates), genetic information processing, cell motility and signal transduction [31, 34], the unsurprising functions in the core genome. Additionally, many clostridial core genes are associated with virulence, including toxins, cell surface proteins, flagellar proteins and antibiotic resistance factors [34]. Our study is in line with previous findings, with the core genome of 965 genes, present in the most prevalent strains. Apart from typical house-keeping pathways, we have identified several KEGG pathways associated with virulence such as betaLactam and vancomycin resistance, biofilm formation and flagellar assembly.

It is believed that highly adaptive metabolism is one of the key contributors to $C$. difficile virulence. $C$. difficile has two main energy sources: aminoacids and sugars. Some aminoacids (such as leucine, valine, proline) contribute to ATP formation via the so-called Stickland pathway [39] while other aminoacids (including cysteine, threonine, serine) and sugars contribute to energy production via central carbon metabolism and TCA cycle [40]. Furthermore, $C$. difficile exhibits some autotrophic characteristics, including genes from the WoodLjungdahl pathway in 4 sequenced genomes that allow 
Table 2 Genes with functional annotation, with sites under positive selection pressure in recurrent but not in single infections. Pvalues are given for log-likelihood ratio test between M1a and M2a models with or without adjustment for multiple hypothesis testing. Adjusted $p$-values $<0.05$ were considered significant

\begin{tabular}{|c|c|c|c|c|}
\hline gene & pvalue-recurrent & pvalue-single & padjust-recurrent & padjust-single \\
\hline $\operatorname{tyr} B$ & $2.12 \mathrm{E}-05$ & 9.97E-01 & $3.21 \mathrm{E}-04$ & $1.00 \mathrm{E}+00$ \\
\hline$c d d 3$ & $6.02 \mathrm{E}-12$ & 1.06E-01 & $1.63 \mathrm{E}-10$ & $1.00 E+00$ \\
\hline fatc & 1.10E-04 & 7.96E-01 & $1.45 \mathrm{E}-03$ & $1.00 \mathrm{E}+00$ \\
\hline opuCC & $1.41 \mathrm{E}-03$ & $6.55 E-01$ & $1.46 \mathrm{E}-02$ & $1.00 \mathrm{E}+00$ \\
\hline$a s n B$ & $2.22 \mathrm{E}-07$ & 8.77E-02 & 4.23E-06 & $1.00 \mathrm{E}+00$ \\
\hline$g / s A$ & $1.81 \mathrm{E}-07$ & 9.70E-01 & 3.59E-06 & $1.00 \mathrm{E}+00$ \\
\hline gltA & 8.87E-05 & 9.96E-01 & $1.23 \mathrm{E}-03$ & $1.00 E+00$ \\
\hline group_18063 & 1.90E-03 & 9.97E-01 & 1.77E-02 & $1.00 E+00$ \\
\hline selA & $1.71 \mathrm{E}-03$ & 5.32E-02 & 1.66E-02 & $1.00 E+00$ \\
\hline $\operatorname{prdF}$ & $0.00 \mathrm{E}+00$ & $9.60 \mathrm{E}-01$ & $0.00 \mathrm{E}+00$ & $1.00 \mathrm{E}+00$ \\
\hline rapl & $1.26 \mathrm{E}-07$ & 8.07E-01 & 2.66E-06 & $1.00 \mathrm{E}+00$ \\
\hline chec & 2.29E-03 & 7.83E-01 & $2.11 \mathrm{E}-02$ & $1.00 \mathrm{E}+00$ \\
\hline$m \operatorname{tnN}$ & 1.89E-05 & 7.46E-01 & $2.95 \mathrm{E}-04$ & $1.00 E+00$ \\
\hline $\operatorname{acc} A$ & 5.01E-03 & $6.96 \mathrm{E}-01$ & 4.09E-02 & $1.00 \mathrm{E}+00$ \\
\hline gph & 2.73E-03 & 5.43E-01 & 2.43E-02 & $1.00 E+00$ \\
\hline hpt & $3.15 \mathrm{E}-03$ & 8.94E-01 & 2.70E-02 & $1.00 \mathrm{E}+00$ \\
\hline hydE & $1.06 \mathrm{E}-04$ & 9.99E-01 & 1.44E-03 & $1.00 E+00$ \\
\hline actl & $1.14 \mathrm{E}-03$ & $9.16 \mathrm{E}-01$ & $1.25 \mathrm{E}-02$ & $1.00 \mathrm{E}+00$ \\
\hline folc & $0.00 E+00$ & 9.83E-01 & $0.00 E+00$ & $1.00 \mathrm{E}+00$ \\
\hline$x y / A$ & 4.29E-15 & $9.78 \mathrm{E}-01$ & 1.30E-13 & $1.00 \mathrm{E}+00$ \\
\hline $\operatorname{cs} d A$ & $1.63 \mathrm{E}-171$ & 9.09E-01 & $1.05 E-169$ & $1.00 E+00$ \\
\hline dacF & 1.62E-09 & 4.24E-02 & 3.89E-08 & 8.73E-01 \\
\hline$t c d B$ & 7.06E-20 & 1.31E-02 & 3.03E-18 & 3.98E-01 \\
\hline rnr & 7.34E-16 & 8.11E-01 & 2.52E-14 & $1.00 \mathrm{E}+00$ \\
\hline $\operatorname{reg} B$ & 2.47E-07 & $6.61 \mathrm{E}-03$ & 4.54E-06 & 2.43E-01 \\
\hline
\end{tabular}

an autotrophic growth by generating energy from $\mathrm{CO}_{2}$ and $\mathrm{H}_{2}$ via this pathway [41]. Production of toxin $\mathrm{A}$ and $\mathrm{B}$ is also correlated with alterations in central carbon metabolism with fluxes changing from butanoate to lactate synthesis [42]. In our work, genes whose presence

Table 3 Types of plasmids discovered is sequenced strains

\begin{tabular}{llll}
\hline Plasmid ID & Copy number & SampleID & Type of infection \\
\hline pCD6 & 4.06 & $3364 \mathrm{M} 15$ & Recurrent \\
DSM 1296 & 3.14 & $712 \mathrm{M} 15$ & Recurrent \\
pCD6 & 6.18 & $500 \mathrm{M} 12$ & Single \\
pCD6 & 4.43 & $3309 \mathrm{M} 13$ & Recurrent \\
pCD6 & 3.39 & 178938 & Single \\
pCD6 & 4.29 & $3544 \mathrm{M} 15$ & Recurrent \\
pCDB11 & 2.84 & $925 \mathrm{M} 12$ & Single \\
DSM 1296 & 2.79 & $925 \mathrm{M} 12$ & Single \\
pCD6 & 5.67 & $2401 \mathrm{M} 11$ & Recurrent \\
pCDBI1 & 2.6 & $561 \mathrm{M} 17$ & Single \\
\hline
\end{tabular}

increased the odds the reinfection are mainly associated with metabolism and energy production: Oxidative phosphorylation, Carbon metabolism, 2-Oxocarboxylic acid metabolism and Carbon fixation in photosynthetic organisms. This may suggest that infection recurrence is associated with altered metabolism and alternative means of energy production rather than the presence of additional virulence factors. However, the practical significance of this discovery in the aspect of new antimicrobial targets for $C$. difficile remains to be uncovered. Historically, bacterial central metabolism (including carbon metabolism) has not been reported as a potential source of new antimicrobial targets, since it has been believed that homology between crucial microbial and human enzymes is simply too high [43]. On the other hand, recent studies identified potential antimicrobial drug targets within carbon metabolism and fixation pathways in MRSA [44] and Mycobacterium tuberculosis [45]. While the aforementioned works are based on in silico methods, their practical utility remains to be proven. 
Table 4 Prophage sequences present in sequenced clostridial genomes. Pvalue $-p$-value in Fisher's exact test, padjust - $p$-value, adjusted for multiple hypothesis testing, odds ratio - odds of recurrent infection, \%single/recurrent - percentage of sequences with prophage present in single/recurrent infections. Adjusted $p$-values $<0.05$ were considered significant

\begin{tabular}{|c|c|c|c|c|c|}
\hline & pvalue & padjust & $\begin{array}{l}\text { odds } \\
\text { ratio }\end{array}$ & \%single & $\%$ recurrent \\
\hline Prophage_134287341 NC_009231 putative scaffold protein \{Clostridium phage phiC2\} & 4.85E-03 & 1.60E-01 & 0.11 & $17 \%$ & $2 \%$ \\
\hline Prophage_90592671 NC_007917 putative lysin \{Clostridium phage phi CD119\} & $6.91 \mathrm{E}-03$ & 1.60E-01 & 0.26 & $31 \%$ & $10 \%$ \\
\hline Prophage_90592670 NC_007917 putative holin \{Clostridium phage phi CD119\} & $1.50 \mathrm{E}-02$ & $1.60 \mathrm{E}-01$ & 0.32 & $81 \%$ & $57 \%$ \\
\hline Prophage_80159693 NC_007581 putative IS transposase (OrfA) \{Clostridium phage c-st\} & 1.64E-02 & 1.60E-01 & 0.23 & $19 \%$ & $5 \%$ \\
\hline $\begin{array}{l}\text { Prophage_90592681 NC_007917 repR RepR putative repressor \{Clostridium phage phi } \\
\text { CD119\} }\end{array}$ & $1.64 \mathrm{E}-02$ & 1.60E-01 & 0.23 & $19 \%$ & $5 \%$ \\
\hline Prophage_90592642 NC_007917 putative head protein \{Clostridium phage phi CD119\} & 1.84E-02 & 1.60E-01 & 0.08 & $11 \%$ & $1 \%$ \\
\hline $\begin{array}{l}\text { Prophage_134287355 NC_009231 putative tail tape measure protein \{Clostridium phage } \\
\text { phiC2\} }\end{array}$ & 3.02E-02 & 2.07E-01 & 0.33 & $28 \%$ & $11 \%$ \\
\hline Prophage_134287357 NC_009231 putative hydrolase \{Clostridium phage phiC2\} & $3.24 \mathrm{E}-02$ & 2.07E-01 & 0.20 & $14 \%$ & $3 \%$ \\
\hline Prophage_134287371 NC_009231 putative amidase/endolysin \{Clostridium phage phiC2\} & $3.60 \mathrm{E}-02$ & 2.07E-01 & 0.31 & $22 \%$ & $8 \%$ \\
\hline Prophage_134287356 NC_009231 putative LysM \{Clostridium phage phiC2\} & 4.20E-02 & 2.07E-01 & 0.27 & $19 \%$ & $6 \%$ \\
\hline Prophage_90592656 NC_007917 xkdP XkdP protein \{Clostridium phage phi CD119\} & 4.37E-02 & 2.07E-01 & 0.40 & $78 \%$ & $58 \%$ \\
\hline
\end{tabular}

Virulence-conferring plasmids are common in enteropathogenic bacteria, such as Shigella spp [46] and Escherichia coli [47]. They contribute to bacterial virulence by carrying genes associated with resistance against antimicrobial agents (such as plasmids R100 in Shigella flex$n e r i 2 b$ which contributes to resistance to sulfonamides, chloramphenicol, tetracyclines and streptomycin [48]) as well as host cell adhesion and invasion (plasmid pO157 in E. coli [49]). Two main plasmids were described in C.difficile: pCD6 [50] and pCD630 [27] - both are relatively small (less than $10 \mathrm{~kb}$ ) in comparison with virulenceconferring plasmids, such as pO157, which is $93.6 \mathrm{~kb}$ in size [51]. Recently, plasmids larger than $40 \mathrm{~kb}$ were discovered [52]. However, while historically plasmid-typing was found to be useful in tracing and typing nosocomial CDI $[53,54]$, no clear associations between virulence and plasmid presence could be drawn for $C$. difficle [52, 55]. Only recently a plasmid pMETRO, conferring resistance to metronidazole has been discovered [56]. In our study, plasmids were discovered in $6.7 \%$ isolates. None of the isolates were resistant to metronidazole and unsurprisingly pMETRO was not discovered in any of them. There was no statistically significant difference between plasmid fraction detected in one-time and recurrent infection isolates. Therefore, we believe our study reinforces the hypothesis that plasmids contribute little to $C$. difficile virulence and recurrence.

Prophages contribute to the evolution and virulence of most bacterial pathogens, including virulence and recurrence of $C$. difficile [57-59]. Prophages are abundant within C. difficile genome - up to 2018 , at least 26 mobile element sequences were described [60]. They manifest a large variety of functions in $C$. difficile: while CD119 represses expression of five clostridial pathogenicity locus (PaLoc) genes [61], other prophages may promote virulence: upon infection with CD38-2, up to two-fold rise in toxin $\mathrm{A}$ and $\mathrm{B}$ was detected in hypervirulent BI/NAP1/027 (ST1) strain [58]. Another prophage, Semix9P1, was determined to carry a fully functional binary toxin [62]. In our study, prophage fragments were discovered, coming from two phages: CD119 and C2. Phage CD119 contains a gene, encoding RepR protein, which downregulates the expression of toxins $\mathrm{A}$ and $\mathrm{B}$ indirectly controlling the expression of tcdR, the toxin gene regulator [61]. RepR gene was found in almost $20 \%$ of single infection isolates and only in 5\% recurrent infection isolates. This may suggest weakened virulence due to the prophage infection at least in some of the single infection isolates. On the other hand, phage $\mathrm{C} 2$ infection was found to affect the measured levels of toxin $\mathrm{B}$ in $\mathrm{C}$. difficile isolates through the production of holins, proteins that disrupt the membrane and increase bacterial secretion [63]. However, after correction for multiple hypothesis testing none of 11 prophage elements uncovered in this study, including $\mathrm{C} 2$ phage originated holins, differed in frequency between single and recurrent infections.

Finally, high adaptability and increased virulence may be attributed to the beneficial point mutations which do not become subject to purifying selection. While it is expected for the core genome to be highly conserved, some of the clostridial core genes were found to be under positive selection. For instance, $\mathrm{He}$ et al. [24] identified 12 such sequences, including membrane proteins and response regulators. The $\mathrm{dN} / \mathrm{dS}$ ratios for core genomes were higher than 1 for both strains analyzed by Murillo et al. [30] Recently, Kumar et al. [32] have proposed that C. difficile is undergoing active speciation and characterized 
genes under positive selective pressure which were associated with sporulation and sugars' metabolism. In our study, more genes were found to be under positive selective pressure in recurrent infection isolates that in single ones. While this may point to higher genetic adaptability of recurrent isolates, in this case other explanations should be also considered. First of all, we had a larger number of sequences from recurrent isolates, which increases probability of detecting positive selection. In addition, in closely related lineages the $\mathrm{dN} / \mathrm{dS}$ ratios were proved to be higher since the purifying selection did not have time to purge mutations [64]. Nevertheless, genes under positive selection in recurrent infections in our study seem to share some of the characteristics with those designated by $\mathrm{He}$ et al. and Kumar et al. [24, 32]. In line with $\mathrm{He}$ et al., we have $\mathrm{ABC}$ transporters $(c d d 3, f a t C$ and $o p u C C)$ and two-component system members (regB) with sites under positive selection. We have also observed changes in metabolism, but they concern aminoacids rather than sugars, similar to Kumar et al. study. Interestingly, toxin B also has been found to be under positive selective pressure in recurrent isolates. Toxin $\mathrm{B}$ was found to be crucial in $C$. difficile virulence [65], with toxin $\mathrm{B}(+)$ toxin $\mathrm{A}(-)$ mutants being fully virulent, while in the reverse situation the virulence is attenuated [66]. Genetic variability within toxin sequences is a well-known phenomenon [67], with 34 toxinotypes currently defined [68]. While our results may suggest an existing selective pressure on toxin B gene, it is also worth noting that most of the toxinotypes are known since the beginning of research on the subject and on a larger scale prevalence of alternative toxinotypes is attributable to local outbreaks [67].

\section{Conclusions}

To conclude, we have managed to thoroughly analyze how genetic mobility influences infection recurrence in CDI. We have confirmed the lack of significance of plasmid-related virulence, as well as reinforced the role of prophages in the virulence-related mechanisms. This seems to be of particular importance since phage therapy seems like a beneficial alternative due to limited antibiotics available for the treatment of CDI [69]. We have also observed changes in metabolism-related genes, both in prevalence (shell genes), as well as in conservation (core genes).

\section{Methods}

Research involving human data was performed in accordance with the Declaration of Helsinki.

The study was approved by the Maria SkłodowskaCurie National Research Institute of Oncology Ethics Committee (number 40/2018). In line with the opinion of the Bioethics Committee at Maria Skłodowska-Curie National Research Institute of Oncology our study did not require informed consent for the following reasons: This is a retrospective study describing the genetic differences between $C$. difficile strains but not between patients; bacterial strains were isolated during routine diagnostics and then banked over the course of one to 10 years; most of these patients are already dead.

As reported recently [70], between 2008 and 2018, all patients hospitalized at the Department of Lymphoma with healthcare-associated diarrhea (defined as $\geq 3$ stools within a 24-h period arising over the third day after hospital admission) underwent testing at the Department of Clinical Microbiology to detect pathogenic C. difficile toxins $\mathrm{A}$ and $\mathrm{B}$. Tests were performed using the $C$. difficile TOX A/B kit (TechLab). Subcultured single colonies from 134 available culture-positive isolates were subjected to whole-genome sequencing (WGS) on Ion Torrent PGM sequencer. Of these, 36 isolates were recovered from patients (18 women and 18 men) with a single CDI, and 98 were recovered from 44 patients (19 women and 25 men) with multiple CDIs. Multi-locus sequence typing results are taken from this publication as well.

\section{Genome assembly and annotation}

The sequenced genomes were assembled with MIRA 5 (https://sourceforge.net/projects/mira-assembler/) genome assembler [71], using parameters set specific for Ion Torrent sequencing technology. The assembled sequences were annotated with prokka [72] version 1.13 (https://github.com/tseemann/prokka), using a minimal contig length of 1000 , proteins from RT027 CD196 strain as a list of trusted proteins and a "metagenome" option to improve annotation in case of large genome fragmentation. The pan-genome calculation was conducted with roary [73] version 3.12 (https://sangerpathogens.github.io/Roary/).

\section{Functional annotation of coding sequences and mobile genetic elements}

The functional annotation of identified CDS was conducted with eggNOG-Mapper [74] version 2.0 (https:// github.com/eggnogdb/eggnog-mapper), using eggNOG [75] categories as well as KEGG [76] pathways. All visualizations were performed with $\mathrm{R}$ package ggplot2 [77]. Mobile elements, specifically the prophages were annotated with VRProfile [78] (https://tool-mml.sjtu.edu.cn/ STEP/STEP_VR.html). Plasmids were identified with PlasmidSeeker [79] (https://github.com/bioinfo-ut/ PlasmidSeeker).

\section{Gene presence as a predictor of disease recurrence}

The influence of a single gene on odds of disease recurrence was assessed with a logistic regression model, with ST as a confounding variable. The analysis was 
conducted only for genes present in more than $15 \%$ and less than $90 \%$ of cases. The $p$-values from this model on a PHRED scale (i.e. transformed with negative logarithm with base 10) served as metric for GSEA (Gene Set Enrichment Analysis) conducted with function from Cluster Profiler [80] package, with 10,000 permutations and maximum gene set size of 200 . The metric was negative for genes which decreased the odds of recurrence.

\section{Gene conservation in recurrent and one-time infections}

In order to compute gene conservation, the CDSs of core genes from STs 1 and 42 were translated into proteins with translate function from BioStrings $\mathrm{R}$ package [81] version 2.46 and option to resolve ambiguous codons. The sequences were then aligned with msa function from $\mathrm{R}$ package msa [82] version 1.14 (using default parameters and default aligner ClustalW [83]). The protein alignment was then converted to codon alignment with pal2nal script [84]. The presence of genetic recombination was verified with PhiPack [85] software and analysis was not continued only if the sequences passed 2 tests present in the package. The $\mathrm{dN} / \mathrm{dS}$ ratios among different sites were then assessed with codeml (part of PAML4 [86] package - http://abacus.gene.ucl.ac.uk/ software/paml.html), using a comparison of two models - nearly neutral (designed M1a in PAML manual http://abacus.gene.ucl.ac.uk/software/pamlDOC.pdf) and positive selection (M2a). $P$-values were adjusted for multiple testing with Benjamini-Hochberg FDR correction [87].

\section{Supplementary Information}

The online version contains supplementary material available at https://doi. org/10.1186/s12866-021-02090-9.

Additional file 1 Further data are available as Supplementary Tables:

Table S1. COG categories prevalence in C. difficile core genome. Table S2. KEGG pathways present in core genome. Table S3. Logistic regression results for odds of infection recurrence after adjustment for ST. Table S4. Gene set enrichment analysis for results of logistic regression. Table S5. Log-likelihood ratio test results for comparison between M2a and M1a models. Table S6. Fisher's exact test results for prevalence difference in prophage sequence between single and recurrent infections.

\section{Authors' contributions}

Conceptualization: JO, EW, MK; Methodology: MK, MM; Formal analysis: MK; Investigation: EW, FA, AP, KS, PC; Resources: ŁT, JW, JO; Data Curation: MK; Writing - original draft preparation: MK,JO; Writing - Review and Editing: MM; Visualization: MK; Supervision: JO; Project administration: JO,AP; Funding acquisition: JO. The author(s) read and approved the final manuscript.

\section{Funding}

This study was supported by National Science Centre (Narodowe Centrum Nauki) [grant number the 2017/27/B/NZ5/01504, awarded to JO]. The study sponsor had no role in study design; in the collection, analysis and interpretation of data; in the writing of the report; and in the decision to submit the article for publication.

\section{Availability of data and materials}

The datasets generated for this study can be found as raw fastq files in Sequence Read Archive with accession number PRJNA608241 (https://www. ncbi.nlm.nih.gov/bioproject/PRJNA608241/).

\section{Ethics approval and consent to participate}

The studies involving human participants were reviewed and approved by Bioethics Committee at Maria Skłodowska-Curie National Research Institute of Oncology. In line with the opinion of the Bioethics Committee at Maria Skłodowska-Curie National Research Institute of Oncology our study did not require informed consent for the following reasons: This is a retrospective study describing the genetic differences between $C$. difficile strains but not between patients; bacterial strains were isolated during routine diagnostics and then banked over the course of one to 10 years; most of these patients are already dead.

\section{Consent for publication}

Not applicable.

\section{Competing interests}

The authors declare that they have no competing interests.

\section{Author details}

${ }^{1}$ Department of Genetics, Maria Sklodowska-Curie National Research Institute of Oncology, Roentgena 5, 02-781 Warsaw, Poland. ${ }^{2}$ Department of Gastroenterology, Hepatology and Clinical Oncology, Centre of Postgraduate Medical Education, 02-781, Warsaw, Poland. ${ }^{3}$ Department of Clinical Microbiology, Maria Sklodowska-Curie National Research Institute of Oncology, 02-781 Warsaw, Poland. ${ }^{4}$ Department of Lymphoproliferative Diseases, Maria Sklodowska-Curie National Research Institute of Oncology, 02-781 Warsaw, Poland.

Received: 15 October 2020 Accepted: 8 January 2021

Published online: 28 January 2021

\section{References}

1. Lawson PA, Citron DM, Tyrrell KL, Finegold SM. Reclassification of Clostridium difficile as Clostridioides difficile (hall and OToole 1935) Prévot 1938. Anaerobe. 2016:40:95-9.

2. Leffler DA, Lamont JT. Clostridium difficile Infection. N Engl J Med. 2015;372: 1539-48.

3. Czepiel J, et al. Clostridium difficile infection: review. Eur J Clin Microbiol Infect Dis. 2019;38:1211-21.

4. Ofosu A. Clostridium difficile infection: a review of current and emerging therapies. Ann Gastroenterol. 2016;29:147-54.

5. Bagdasarian N, Rao K, Malani PN. Diagnosis and treatment of Clostridium difficile in adults: a systematic review. JAMA. 2015;313:398-408.

6. Healthcare-associated infections: Clostridium difficile infections. (2018).

7. Bauer MP, et al. Clostridium difficile infection in Europe: a hospital-based survey. Lancet. 2011:377:63-73.

8. Debast SB, Bauer MP, Kuijper E. J \& European Society of Clinical Microbiology and Infectious Diseases European Society of Clinical Microbiology and Infectious Diseases: update of the treatment guidance document for Clostridium difficile infection. Clin Microbiol Infect. 2014; 20(Suppl 2):1-26.

9. Singh T, et al. Updates in treatment of recurrent Clostridium difficile infection. J Clin Med Res. 2019;11:465-71.

10. Song JH, Kim YS. Recurrent Clostridium difficile infection: risk factors, treatment, and prevention. Gut Liver. 2019:13:16-24.

11. Aslam S, Hamill RJ, Musher DM. Treatment of Clostridium difficile-associated disease: old therapies and new strategies. Lancet Infect Dis. 2005;5:549-57.

12. Garey KW, Sethi S, Yadav Y, DuPont HL. Meta-analysis to assess risk factors for recurrent Clostridium difficile infection. J Hosp Infect. 2008;70:298-304.

13. Cho SM, Lee JJ, Yoon HJ. Clinical risk factors for Clostridium difficileassociated diseases. Braz J Infect Dis. 2012;16:256-61.

14. Appaneal HJ, Caffrey AR, Beganovic M, Avramovic S, LaPlante KL. Predictors of Clostridioides difficile recurrence across a national cohort of veterans in outpatient, acute, and long-term care settings. Am J Health Syst Pharm. 2019;76:581-90

15. Eyre DW, et al. Predictors of first recurrence of Clostridium difficile infection: implications for initial management. Clin Infect Dis. 2012;55:S77-87. 
16. Pepin J, et al. Increasing risk of relapse after treatment of Clostridium difficile colitis in Quebec, Canada. Clin Infect Dis. 2005:40:1591-7.

17. Deshpande A, et al. Risk factors for recurrent Clostridium difficile infection: a systematic review and meta-analysis. Infect Control Hosp Epidemiol. 2015; 36:452-60.

18. Abou Chakra CN, et al. Factors associated with complications of Clostridium difficile infection in a multicenter prospective cohort. Clin Infect Dis. 2015; 61:1781-8.

19. Avni $\mathrm{T}$, et al. Clostridioides difficile infection in immunocompromised hospitalized patients is associated with a high recurrence rate. Int J Infect Dis. 2020;90:237-42.

20. Revolinski SL, Munoz-Price LS. Clostridium difficile in Immunocompromised hosts: a review of epidemiology, risk factors, treatment, and prevention. Clin Infect Dis. 2019;68:2144-53.

21. Gaulton T, et al. Complete genome sequence of the Hypervirulent bacterium Clostridium difficile strain G46, Ribotype 027. Genome Announc 2015:3:e00073-15.

22. Brouwer MSM, Allan E, Mullany P, Roberts AP. Draft genome sequence of the nontoxigenic Clostridium difficile strain CD37. J Bacteriol. 2012;194: 2125-6.

23. Stabler RA, et al. Comparative genome and phenotypic analysis of Clostridium difficile 027 strains provides insight into the evolution of a hypervirulent bacterium. Genome Biol. 2009;10:R102.

24. He M, et al. Evolutionary dynamics of Clostridium difficile over short and long time scales. PNAS. 2010;107:7527-32.

25. Knight DR, Elliott B, Chang BJ, Perkins TT, Riley TV. Diversity and evolution in the genome of Clostridium difficile. Clin Microbiol Rev. 2015;28:721-41.

26. Kansau I, et al. Deciphering adaptation strategies of the epidemic Clostridium difficile 027 strain during infection through in vivo transcriptional analysis. PLoS One. 2016;11:e0158204.

27. Sebaihia M, et al. The multidrug-resistant human pathogen Clostridium difficile has a highly mobile, mosaic genome. Nat Genet. 2006:38:779-86.

28. Stabler RA, et al. In-depth genetic analysis of Clostridium difficile PCRribotype 027 strains reveals high genome fluidity including point mutations and inversions. Gut Microbes. 2010;1:269-76.

29. Didelot $X$, et al. Microevolutionary analysis of Clostridium difficile genomes to investigate transmission. Genome Biol. 2012;13:R118.

30. Murillo T, et al. Two groups of Cocirculating, Epidemic Clostridiodes difficile Strains Microdiversify through Different Mechanisms. Genome Biol Evol. 2018;10:982-98.

31. Scaria J, et al. Analysis of ultra low genome conservation in Clostridium difficile. PLoS One. 2010;5:e15147.

32. Kumar N, et al. Adaptation of host transmission cycle during Clostridium difficile speciation. Nat Genet. 2019;51:1315-20.

33. Forgetta $V$, et al. Fourteen-genome comparison identifies DNA markers for severe-disease-associated strains of Clostridium difficile. J Clin Microbiol. 2011:49:2230-8.

34. Janvilisri T, et al. Microarray identification of Clostridium difficile Core components and divergent regions associated with host origin. J Bacteriol. 2009;191:3881-91.

35. Hiller NL, et al. Comparative genomic analyses of seventeen Streptococcus pneumoniae strains: insights into the pneumococcal supragenome. J Bacteriol. 2007:189:8186-95.

36. Dembek M, et al. High-Throughput Analysis of Gene Essentiality and Sporulation in Clostridium difficile. mBio. 2015;6:02383-14.

37. Poulsen BE, et al. Defining the core essential genome of Pseudomonas aeruginosa. PNAS. 2019;116:10072-80

38. Willcocks SJ, Stabler RA, Atkins HS, Oyston PF, Wren BW. High-throughput analysis of Yersinia pseudotuberculosis gene essentiality in optimised in vitro conditions, and implications for the speciation of Yersinia pestis. BMC Microbiol. 2018;18:46.

39. Stickland LH. Studies in the metabolism of the strict anaerobes (genus Clostridium). Biochem J. 1934;28:1746-59.

40. Neumann-Schaal M, Jahn D, Schmidt-Hohagen K. Metabolism the Difficile way: the key to the success of the pathogen Clostridioides difficile. Front Microbiol. 2019:10:219.

41. Köpke M, Straub M, Dürre P. Clostridium difficile is an autotrophic bacterial pathogen. PLoS One. 2013;8:e62157.

42. Hofmann JD, et al. Metabolic reprogramming of Clostridioides difficile during the stationary phase with the induction of toxin production. Front Microbiol. 2018;9:1970
43. Murima P, McKinney JD, Pethe K. Targeting Bacterial Central Metabolism for Drug Development. Chem Biol. 2014:21:1423-32.

44. Haag NL, Velk KK, Wu C. Potential antibacterial targets in bacterial central metabolism. Int J Adv Life Sci. 2012:4:21-32.

45. Katiyar A, Singh $\mathrm{H}$, Azad KK. Identification of missing carbon fixation enzymes as potential drug targets in mycobacterium tuberculosis. J Integr Bioinform. 2018;15:20170041.

46. Yang F, et al. Genome dynamics and diversity of Shigella species, the etiologic agents of bacillary dysentery. Nucleic Acids Res. 2005;33:6445-58.

47. Kaper JB, Nataro JP, Mobley HLT. Pathogenic Escherichia coli. Nat Rev Microbiol. 2004:2:123-40

48. Womble DD, Rownd RH. Genetic and physical map of plasmid NR1: comparison with other IncFll antibiotic resistance plasmids. Microbiol Rev. 1988;52:433-51

49. Lim JY, Yoon JW, Hovde CJ. A brief overview of Escherichia coli O157:H7 and its plasmid 0157. J Microbiol Biotechnol. 2010;20:5-14.

50. Purdy D, et al. Conjugative transfer of clostridial shuttle vectors from Escherichia coli to Clostridium difficile through circumvention of the restriction barrier. Mol Microbiol. 2002:46:439-52.

51. Schmidt H, Kernbach C, Karch H. Analysis of the EHEC hly operon and its location in the physical map of the large plasmid of enterohaemorrhagic Escherichia coli O157:H7. Microbiology. 1996;142:907-14.

52. Amy J, et al. Identification of large cryptic plasmids in Clostridioides (Clostridium) difficile. Plasmid. 2018;96-97:25-38.

53. Clabots CR, Peterson LR, Gerding DN. Characterization of a nosocomial Clostridium difficile outbreak by using plasmid profile typing and clindamycin susceptibility testing. J Infect Dis. 1988;158:731-6.

54. Steinberg JP, Beckerdite ME, Westenfelder GO. Plasmid profiles of Clostridium difficile isolates from patients with antibiotic-associated colitis in two community hospitals. J Infect Dis. 1987:156:1036-8.

55. Hornung BVH, Kuijper EJ, Smits WK. An in silico survey of Clostridioides difficile extrachromosomal elements. Microb Genom. 2019:5:e000296.

56. Boekhoud IM, et al. Plasmid-mediated metronidazole resistance in Clostridioides difficile. Nat Commun. 2020:11:598.

57. Hargreaves KR, Colvin HV, Patel KV, Clokie JJP, Clokie MRJ. Genetically diverse Clostridium difficile strains harboring abundant Prophages in an estuarine environment. Appl Environ Microbiol. 2013;79:6236-43.

58. Sekulovic O, Meessen-Pinard M, Fortier L-C. Prophage-stimulated toxin production in Clostridium difficile NAP1/027 Lysogens. J Bacteriol. 2011;193: 2726-34.

59. Meessen-Pinard M, Sekulovic O, Fortier L-C. Evidence of in vivo Prophage induction during Clostridium difficile infection. Appl Environ Microbiol. 2012; 78:7662-70

60. Fortier L-C. Bacteriophages contribute to shaping Clostridioides (Clostridium) difficile species. Front Microbiol. 2018;9:2033.

61. Govind R, Vediyappan G, Rolfe RD, Dupuy B, Fralick JA. Bacteriophagemediated toxin gene regulation in Clostridium difficile. J Virol. 2009:83: 12037-45.

62. Riedel T, et al. A Clostridioides difficile bacteriophage genome encodes functional binary toxin-associated genes. J Biotechnol. 2017;250:23-8.

63. Goh S, Chang BJ, Riley TV. Effect of phage infection on toxin production by Clostridium difficile. J Med Microbiol. 2005;54:129-35.

64. Rocha EPC, et al. Comparisons of $\mathrm{dN} / \mathrm{dS}$ are time dependent for closely related bacterial genomes. J Theor Biol. 2006;239:226-35.

65. Carter GP, Rood Jl, Lyras D. The role of toxin a and toxin B in Clostridium difficile-associated disease. Gut Microbes. 2010;1:58-64.

66. Carter GP, et al. Defining the Roles of TcdA and TcdB in Localized Gastrointestinal Disease, Systemic Organ Damage, and the Host Response during Clostridium difficile Infections. mBio. 2015;6:e00551.

67. Rupnik M. Heterogeneity of large clostridial toxins: importance of Clostridium difficile toxinotypes. FEMS Microbiol Rev. 2008;32:541-55.

68. Rupnik M, Janezic S. An update on Clostridium difficile Toxinotyping. J Clin Microbiol. 2016:54:13-8.

69. Phothichaisri $W$, et al. Characterization of bacteriophages infecting clinical isolates of Clostridium difficile. Front Microbiol. 2018:9:1701

70. Waker $\mathrm{E}_{\text {, et }}$ al. High prevalence of genetically related Clostridium Difficile strains at a single Hemato-oncology Ward over 10 years. Front Microbiol. 2020;11:1618.

71. Chevreux B, et al. Using the miraEST assembler for reliable and automated mRNA transcript assembly and SNP detection in sequenced ESTs. Genome Res. 2004;14:1147-59. 
72. Seemann T. Prokka: rapid prokaryotic genome annotation. Bioinformatics. 2014;30:2068-9.

73. Page AJ, et al. Roary: rapid large-scale prokaryote pan genome analysis. Bioinformatics. 2015;31:3691-3.

74. Huerta-Cepas J, et al. Fast genome-wide functional annotation through Orthology assignment by eggNOG-mapper. Mol Biol Evol. 2017;34:2115-22.

75. Huerta-Cepas J, et al. eggNOG 5.0: a hierarchical, functionally and phylogenetically annotated orthology resource based on 5090 organisms and 2502 viruses. Nucleic Acids Res. 2019:47:D309-14.

76. Kanehisa $\mathrm{M}$, et al. Data, information, knowledge and principle: back to metabolism in KEGG. Nucleic Acids Res. 2014;42:D199-205.

77. Wickham H. ggplot2: Elegant Graphics for Data Analysis. New York: springer; 2009.

78. Li J, et al. VRprofile: gene-cluster-detection-based profiling of virulence and antibiotic resistance traits encoded within genome sequences of pathogenic bacteria. Brief Bioinform. 2018;19:566-74.

79. Roosaare M, Puustusmaa M, Möls M, Vaher M, Remm M. PlasmidSeeker: identification of known plasmids from bacterial whole genome sequencing reads. PeerJ. 2018;6:e4588.

80. Yu G, Wang L-G, Han Y, He Q-Y. clusterProfiler: an R package for comparing biological themes among gene clusters. OMICS. 2012;16:284-7.

81. Pagès $H$, Aboyoun $P$, Gentleman R, DebRoy S. Biostrings: Efficient manipulation of biological strings. Biostrings. 2017. https://doi.org/10.18129/ B9.bioc.

82. Bodenhofer U, Bonatesta E. Horejš-Kainrath, C. \& Hochreiter, S. msa: an R package for multiple sequence alignment. Bioinformatics. 2015:31:3997-9.

83. Thompson JD, Higgins DG, Gibson TJ. CLUSTAL W: improving the sensitivity of progressive multiple sequence alignment through sequence weighting, position-specific gap penalties and weight matrix choice. Nucleic Acids Res. 1994:22:4673-80.

84. Suyama M, Torrents D, Bork P. PAL2NAL: robust conversion of protein sequence alignments into the corresponding codon alignments. Nucleic Acids Res. 2006;34:W609-12.

85. Bruen TC, Philippe H, Bryant D. A simple and robust statistical test for detecting the presence of recombination. Genetics. 2006;172:2665-81.

86. Yang Z. PAML 4: phylogenetic analysis by maximum likelihood. Mol Biol Evol. 2007;24:1586-91.

87. Benjamini $Y$, Hochberg Y. Controlling the false discovery rate: a practical and powerful approach to multiple testing. J R Stat Soc B (Methodological). 1995;57:289-300

\section{Publisher's Note}

Springer Nature remains neutral with regard to jurisdictional claims in published maps and institutional affiliations.

Ready to submit your research? Choose BMC and benefit from:

- fast, convenient online submission

- thorough peer review by experienced researchers in your field

- rapid publication on acceptance

- support for research data, including large and complex data types

- gold Open Access which fosters wider collaboration and increased citations

- maximum visibility for your research: over $100 \mathrm{M}$ website views per year

At $\mathrm{BMC}$, research is always in progress.

Learn more biomedcentral.com/submissions 